the views of the various online services nor the USM Alumni Fund.

\section{References \\ Leyden, Peter. 1994. "Life in the Fast Lane?: Not Yet - Heavy Use of Informa- tion Superhighway Has Created Traffic Jams." Minneapolis Star Tribune, 9 Feb- ruary 1994, Sec D. \\ Magid, Larry. 1993. "Adult Proof Caps." Prodigy. \\ Markoff, John. 1989. "Betting on a Different Videotext Idea." New York Times, 12 July 1989 , Sec. D.}

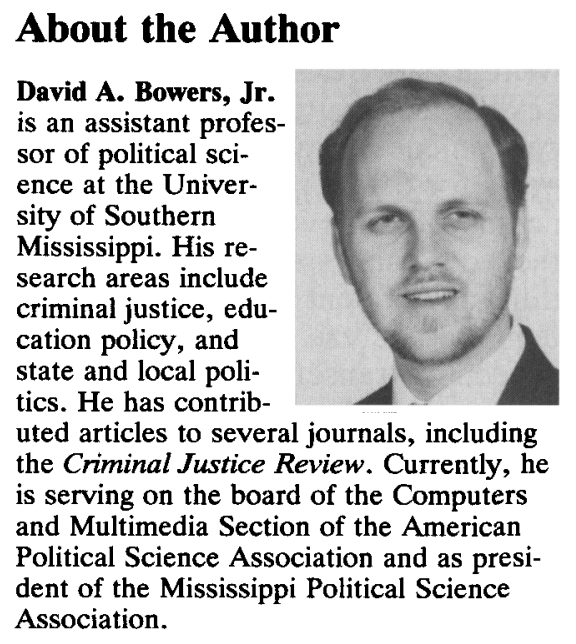

\title{
Revitalizing Undergraduate Programs Through Intercollegiate Mock Trial Competition
}

\author{
John R. Vile and Thomas R. Van Dervort, Middle Tennessee State University
}

\begin{abstract}
Although the movement currently appears more prominent at the high school than the college level, recent years have witnessed an upsurge in law-related education programs. Studies have shown that such programs have been successful not only in educating students about the role of law and other governmental institutions in society but also in reducing criminal activity (Van Dervort 1994, 32).

Because of the proliferation of materials related to law-related education, educators must choose those most suitable to their own objectives and programs. As political scientists who teach law-related courses to undergraduates at a state university, we have found mock trial competition to be a highly effective way of giving our students a first-hand look at how courts operate, leading them to a better understanding of the legal system, and interesting and involving them in our prelaw program.
\end{abstract}

\section{History and Description of Mock Trial Competition}

This year, 1994, marked the tenth year of intercollegiate mock trial competition with over 115 colleges and universities and over 200 teams participating in this activity; this marked a jump from eight schools and twelve teams who had participated in the first national tournament in 1985 (American Mock Trial Association, 1994, 6). The mock trial program received a major boost early in its history in 1985 when the Conference of State Chief Justices meeting in Williamsburg, Virginia, endorsed mock trial competition as a means of promoting greater understanding of the legal system. Initially, the national collegiate tournament was sponsored by the Drake University Law School in Des Moines, Iowa. Richard Calkins, then dean, was influential in establishing mock trial competition, and he has subsequently served as the guiding light of the American Mock Trial Association.

AMTA has now become an independent corporation with an expanding board of directors made up of representatives from undergraduate institutions throughout the country. In addition to the national tournament, AMTA sponsored a variety of invitational tournaments and 11 regional mock trial competi- tions during the 1993-94 school year. These, in turn, qualified students to participate in one of three flights of national competition, two held in Des Moines, Iowa, and the third (primarily for new schools) held at the University of Wisconsin at Milwaukee. The activity is also growing at the high school level, providing colleges and universities with established mock trial programs an effective recruiting tool that is especially appealing to good students.

As the name of the activity suggests, mock trial competition focuses on student enactments of trials. Unlike the corresponding moot court competition that is more common in law schools, undergraduate mock trials focus on state trial courts rather than federal appellate courts. This emphasis provides a balance for students who have taken constitutional law and other undergraduate classes that almost always focus on federal rather than state courts (Galie 1993), and that almost always examine appellate court decisions, thus perpetuating what Jerome Frank once called the "Upper Court Myth" (Frank 1969, 222).

Each year, the American Mock 
Trial Association distributes a hypothetical case, alternatively focusing on a criminal or civil matter. The 1993-94 case centered on a state prosecution for violation of a hate crime statute. The case used in 1992-93 was a hypothetical civil case involving sexual harassment.

The packet provided by AMTA includes a statement of the relevant law, a list of rules adapted to mock trial competition but based on real life trials (with, for example, objections to improper forms of questioning, procedures for impeaching witnesses, and the like), exhibits, and affidavits from witnesses whom the prosecution and defense may call.

During a trial, each side meets with the judges for a pretrial conference, presents opening and closing arguments, holds any needed side bars, and directs and crossexamines three witnesses. Teams have from six to eight participants (depending on how they allocate witness and attorney roles) and are responsible for presenting both sides of the case. In a typical tournament, teams present both sides of a case twice and receive a total of eight ballots from two scoring judges in each round. Teams are scored not according to how the judges would necessarily decide the case but rather according to how well students play their roles as witnesses and attorneys.

\section{Our Experience with Mock Trial Competition}

We began a mock trial program five years ago. At the time we were looking for a way to attract additional students and to further interest and involvement among our existing majors, most of whom chose the prelaw emphasis with the intention of attending law school. Unfortunately, many of these students often failed to grasp the connection between the study of political science and the future practice of law.

Like many schools, our students had formed a prelaw society. While various activities sponsored by this organization-for example, mock LSAT exams, visits to law schools, and guest speakers - helped famil- iarize the students with information about applying to law schools and stimulated some student interest in law, this society did not by itself generate the kind of interest that mock trial participation has engendered.

We began mock trial participation after Marcus Pohlmann, a po-

The mock trial program has helped to revitalize student interest in political science courses and to promote greater cooperation with other departments-speech and criminal justice, for example-on our campus.

litical scientist and mock trial coach at Rhodes College in Memphis, invited us to participate in an invitational tournament on his campus. That year we took a single team to this tournament and subsequently to national competition in Des Moines. Our students returned with great enthusiasm for future competition after winning an outstanding first-year team award.

After a second year of competition and growing student interest, we initiated a one-hour class in courtroom procedures. On average, we now enroll between 40 to 50 students in this program each fall, offering the courtroom procedures class at night where we can follow instruction with scrimmages among our teams. Our program is currently larger than most. Typically, we field six teams at the invitational tournament that we sponsor in November, three teams at regionals at the end of January, and two at nationals at the end of February.

\section{Benefits of Mock Trial Competition}

The mock trial program has helped to revitalize student interest in political science courses and to promote greater cooperation with other departments-speech and criminal justice, for example-on our campus. We have found it particularly refreshing to hear our students discussing mock trial issues outside of classes and making inquiries about law and government based on their experience in this activity.

A prime benefit of mock trial competition is that it involves students in a real-life activity that educates them about the law and about aspects of our governmental system while also developing their skills in speaking, reasoning, and working as a team. Other extracurricular activities can also successfully develop one or more such skills, but there are some unique advantages to mock trial competition.

One advantage is accessibility to entering students whatever their majors. While other forms of public speaking generally require that an individual be prepared to make a solo formal presentation in order to participate, mock trial competition enables shyer and less experienced students to begin with a witness role and take on the more difficult attorney roles as they acquire experience and self-confidence. More like a dramatic production than a speech, mock trial competition offers more excitement than the typical public speaking event.

Because the sizes of teams are larger than in most other public speaking competitions, mock trial competition encourages students to work together, giving them experience in interpersonal relations. While the personal conflicts can sometimes be exasperating for students and coaches alike (with rivalry within and among teams and with team compositions sometimes changing up to the day of competition), they also have much to teach, especially for those students who assume the role of team captain or cocaptain.

While the teaching of undergraduate political science is rarely ori- 
ented directly to careers, mock trial competition is different. It enables students to discover their potential for careers in law related fields by allowing them to participate in an activity that mimics real life and by bringing them in contact with attorneys and judges who help with coaching and judging. We encourage those students who discover that they are not as suited for the profession of law as they thought to consider other career fields, such as teaching, public administration, and international relations.

Whatever careers our students choose, we are convinced that those who do the best will be those who learn the advantages of thorough study and preparation as well as attention to proper procedures. Naturally, we hope we convey this message through classroom assignments. There is something, however, about allowing students to put their own preparation and skills to the test in a formal mock trial setting where they are judged by outside professionals that brings this message home in a unique way. It was especially refreshing to hear one of our seniors say that, of all his college classes and activities, it was mock trial competition that finally showed him the importance of thorough preparation and attention to detail.

At a time when there is increasing concern about the teaching of legal ethics, mock trial competition also teaches something about the appropriate "rules of the game" that are so important for those contemplating entry into the legal profession. We especially emphasize that ethical legal conduct involves adherence to legal rules and proper procedures just as appropriate testimony from witnesses involves close adherence to the statements in their affidavits and avoiding invention of facts. We stress that competition, like real life, requires professional conduct at all times.

In our classes, we sometimes find that students think that cases are decided almost solely on the basis of abstract legal principles. By contrast, students who participate in mock trial competition quickly come to recognize that, while legal principles are important, cases are rarely decided on such principles alone.

It is not infrequent to have judges who split ballots in a round, sometimes with fairly significant gaps in points between them. Students get a real-life appreciation not only for the way that legal rules of evidence and different levels of skill and preparation by one or the other side can influence outcomesnicely illustrating Frank's "fighttheory"' of judging (Frank 1969, 80-102)_but also for the way that the preconceptions and predilections of judges can affect legal verdicts.

. . to hear one of our
seniors say that, of all
his college classes and
activities, it was mock
trial competition that
finally showed him the
importance of thorough
preparation and
attention to detail.

To date at least, the mock trial competitions that we have observed have maintained a connection to their real-life counterparts that is sometimes missing in other forensic activities where the judging is largely done by academic insiders. We think that a great deal of the success of the mock trial enterprise stems from the fact that judges are still recruited from the ranks of members of the bar who will probably judge only one tournament a year and who are accordingly more likely to compare the event to real-life trials than to other academic competitions they have observed. Because, at least in theory, attorneys are making a pitch to a jury, they are encouraged to speak in a measured pace, think of useful examples and analogies, and avoid excessive jargon.

One of the most satisfying things about mock trial competition is that it provides us with a chance to work with students on a personal basis for extended periods. Not only does this allow us the opportunity to correct students' grammar, help them with voice projection and diction, and comment on a host of other important attributes that might sound inappropriate or demeaning if said in a classroom context, but it has also enabled us to learn about our students and their strengths and weaknesses in ways that we would never be able to observe in a classroom. We have observed students who rarely utter a word in class demonstrate wit, tenacity, and/or analytical or speaking skills that we would have been likely otherwise to miss. Such information significantly enhances our work in advising students and in writing letters of recommendation for those who subsequently apply to law or graduate school.

While we try to see that our students do not develop an excessive preoccupation with winning, one of the satisfying aspects of mock trial competition has been the opportunity it has given us to highlight student achievements by sending stories to the campus newspaper and by setting up displays of our trophies in the departmental office and in the library. The national tournament now recognizes the top 10 teams in each division as well as the top 10 attorneys and witnesses (such winners are now designated as "All Americans").

In addition, there are awards for outstanding teams from two-year schools and for outstanding firstyear teams. The latter award influenced our own decision to continue mock trial activity after our first year, and placement of our teams in the top 10 for the last three years has undoubtedly encouraged our students to persist.

We try to emphasize, however, that the poise and skills that our students develop, as well as the heightened interest in legal matters, are always their own reward. Our teams also hold a banquet at the end of the year to recognize all students for their achievements, whether they resulted in a trophy or not. 


\section{How to Start a Mock Trial Program}

Mock trial coaches need not be political scientists, and, at a number of schools, the activity is sponsored by professors in speech or other disciplines. At least in those political science departments with a prelaw emphasis, however, we think that political scientists can be especially effective as coaches and that they will find that their coaching will contribute to the lessons they teach in the classroom.

Marcus Pohlmann has been especially effective as a coach, with his teams capturing the national championship again this year. Other political scientists whom we have come to know who serve as successful coaches (often with help from an area attorney) include Helen Ridley at Kennesaw College, Jim Walker at Wright State University, Otis Stephens at the University of Tennessee, Knoxville, and Don Racheter of the Central University of Iowa.

We have found that mock trial coaching can be an extremely labor-intensive activity. When the activity is shared with other faculty members and area attorneys, however, it need not involve excessive resources. Moreover, beginning colleges might choose to attend only invitational and/or regional tournaments (or even sponsor an in-house invitational tournament) without being obligated to go to nationals. It is also important to allow students to develop their own leadership abilities by taking the initiative in planning scrimmages, working on problems of interpersonal relations, and in otherwise contributing to the success of their teams. Students who start in minor roles in their freshman year sometimes end up serving as team captains or cocaptains in subsequent years.

In our own case, we have found that a one-hour-credit class, while involving only a modest change in our curricular offerings, has been quite helpful in stimulating student interest. Marcus Pohlmann has had similar success with this arrangement at a smaller private liberal arts college (American Mock Trial Association 1994, 31). Both our student government association and our vice-president for academic affairs have helped to fund our teams-with primary expenses being for tournament travel, lodging, and fees. We have chiefly involved members of the local bar in judging tournaments and helping with student critiques, but other colleges and universities have been successful in raising financial support from this source. Given the enthusiasm among our students for our program, we believe that alumni of our mock trial programs will eventually contribute financial support. Some of our graduates who live in the area are already helping us coach and judge.

Considering the commitment it entails, the mock trial experience is not for everyone. We have, however, found the activity to be an effective way to stimulate interest in our undergraduate programs while developing a variety of student abilities and interesting students in careers in law and government.

New mock trial materials are generally available in early September. Professors interested in further information about mock trial competition should contact: Richard $\mathbf{M}$.
Calkins, American Mock Trial Association, 801 Grand Avenue, Suite 3200, Des Moines, Iowa 50309, Phone: (515) 288-3667.

\section{References}

American Mock Trial Association, Tenth Anniversary Program, Des Moines, lowa, February 1994.

Frank, Jerome. 1969. Courts on Trial: Myth and Reality in American Justice. New York: Atheneum.

Galie, Peter. "Teaching Civil Liberties: The Missing Dimension." Perspectives on Political Science 22 (Summer 1993), 11623.

Van Dervort, Thomas. 1994. Equal Justice Under the Law. Minneapolis/St. Paul: West Publishing.

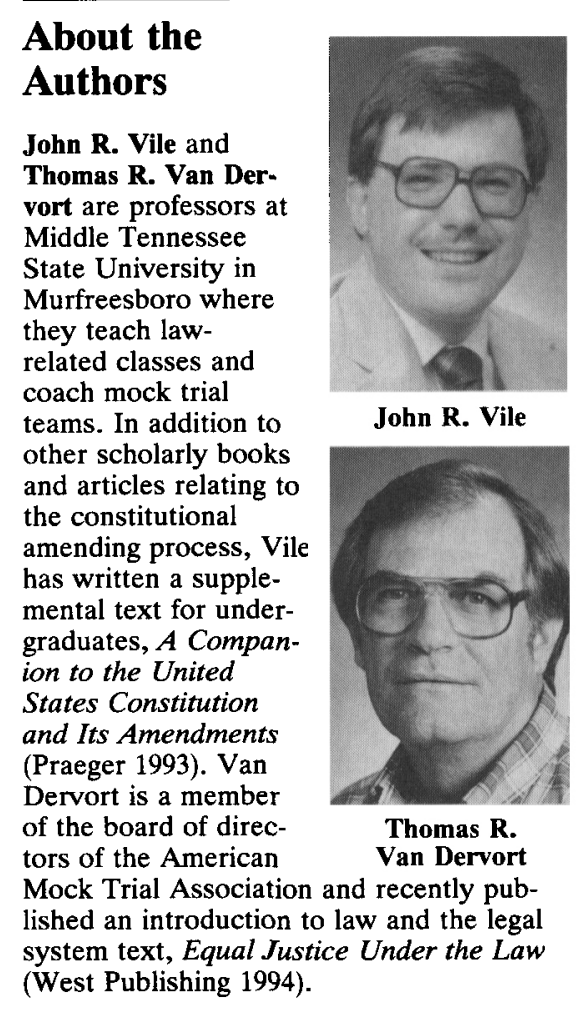

